\title{
Strategies to improve medication adherence in patients with schizophrenia: the role of support services
}

This article was published in the following Dove Press journal:

Neuropsychiatric Disease and Treatment

16 April 2015

Number of times this article has been viewed

\author{
Peggy El-Mallakh \\ Jan Findlay \\ College of Nursing, University \\ of Kentucky, Lexington, KY, USA
}

Correspondence: Peggy El-Mallakh 315 College of Nursing Building, Number 547, College of Nursing, University of Kentucky, Lexington, KY 40536, USA

Email peggy.el-mallakh@uky.edu

\begin{abstract}
The purpose of this review is to describe research over the past 10 years on the role of support services in promoting medication adherence in mental health consumers diagnosed with schizophrenia. A literature search was conducted using the terms "medication adherence," "schizophrenia," and "support services," using Medline, PubMed, and CINAHL. Reference lists from published studies were also reviewed to identify additional research studies. Twenty-two articles focused on support-service intervention studies, and these were selected for review. Available support-service interventions include adherence therapy, electronic reminders via text messages and telephones, cognitive-behavioral and motivational strategies, and financial incentives. Support-service intervention strategies need to be tailored to the specific needs of mental health consumers with schizophrenia. More research is needed to investigate effective support services to enhance long-term adherence and adherence to medications for medical illnesses in this population.
\end{abstract}

Keywords: schizophrenia, medication adherence, support services, therapy, interventions

\section{Introduction}

Adherence to pharmacological treatment is essential for alleviation of psychotic symptoms in schizophrenia. First-line antipsychotic medications are effective in approximately $70 \%-80 \%$ of persons diagnosed with schizophrenia (PWS); however, an estimated $50 \%$ of those who respond well to medications are nonadherent to their treatment regimen. ${ }^{1}$ Wide variations have been observed in patterns of medication adherence among PWS. Nonadherence can range from patients who refuse to take medications due to lack of acceptance of the need for medication, to patients who recognize the need for medication and are committed to treatment but are nonadherent due to forgetfulness or financial constraints. ${ }^{2}$ The consensus definition for adherence maintains that PWS can be considered adherent if they take more than $80 \%$ of prescribed medications; partial adherence is defined as taking $50 \%$ of prescribed medications. ${ }^{3}$ Velligan and colleagues also report a consensus among experts that nonadherence can be defined as being off of medications for 1 week. $^{3}$

\section{Factors associated with medication nonadherence}

As the definitions of adherence suggest, the decision to take medications in PWS is a complex phenomenon that involves multiple patient, environmental, provider, and medication-related factors. Patient-related factors include some demographic characteristics, such as newly starting treatment, younger age at onset of illness, alcohol dependence and other illicit substance use, homelessness, low levels of involvement 
in social activities, independent housing, and financial constraints with consequent inability to afford copayments for prescriptions. ${ }^{4-9}$ Membership in a minority ethnic group also contributes to poor medication adherence; in a large study of 34,128 US veterans with schizophrenia, Valenstein et al ${ }^{10}$ reported that the relative risk ratio for consistently poor adherence was 3.81 for African Americans compared to whites and 3.54 for Hispanics compared to whites. Lack of family support for adherence, or having no family, further contributes to nonadherence. Glick et $\mathrm{al}^{11}$ and Moritz et $\mathrm{al}^{12}$ observed that a positive attitude toward positive symptoms, particularly the perception of importance and power resulting from psychotic symptoms, also contributes to nonadherence. In addition, a study by Jónsdóttir et $\mathrm{al}^{6}$ found that nonadherent PWS had significantly higher IQs, executive functioning, memory, and verbal learning/fluency compared to fully adherent PWS.

Perceptions about illness and medications are very important factors that influence adherence. For example, adherence is higher among PWS who have insight and an awareness of the need to take medications to alleviate symptoms and avoid hospitalization. ${ }^{7,13-15}$ In addition, favorable attitudes toward mediations and the expectation that medications are effective in reducing symptoms contribute to adherence. ${ }^{15,16}$ Intolerable side effects are a major reason for discontinuing medications. ${ }^{12,15}$ For example, side effects associated with typical antipsychotics, such as extrapyramidal symptoms, sedation, and elevated prolactin levels, are particularly problematic. Metabolic side effects of atypical antipsychotics, including weight gain, further contribute to lack of adherence. ${ }^{17}$ However, some research suggests that recognition of the benefits of medications in alleviating troublesome psychotic symptoms improves willingness to tolerate the side-effect burden for the sake of mental wellness. ${ }^{18}$ Similarly, Liu-Seifert et al ${ }^{19}$ compared adherence among 1,103 people treated with olanzapine and 1,090 people treated with other atypical antipsychotic medications (risperidone, quetiapine, ziprasidone, or aripiprazole). Findings suggested that an improvement in the positive symptom rating subscale of the Positive and Negative Syndrome Scale was the strongest predictor of treatment adherence, regardless of the medication that was prescribed.

Much research supports the critical need for a strong and positive therapeutic relationship in the promotion of medication adherence. ${ }^{20,21}$ Misdrahi et $\mathrm{al}^{7}$ found that therapeutic alliance was significantly associated with medication adherence $(r=0.663)$ among 38 PWS. Similarly, Dassa et $\mathrm{al}^{16}$ found that nonadherence to medications increased with a low level of therapeutic alliance (odds ratio $=0.45,95 \%$ confidence interval $=0.32-0.64$ ) among 291 PWS. Research also suggests that patients value support from prescribers regarding medication, particularly when prescribers provided accurate information about potential side effects of medication, expressed understanding of the patient perspective, and listened to patients' concerns about the medications. In addition, Day et $\mathrm{al}^{20}$ reported that the experience of admission to the hospital is an important factor that influences willingness to take medications; the perception of coercion, lack of a voice in treatment decisions, and negative pressure to enter the hospital are all associated with nonadherence to psychiatric medications.

\section{Adherence to medications for medical illnesses}

High rates of cardiometabolic problems among PWS have prompted clinicians to focus on adherence to treatment for medical illnesses in this population. Research investigating adherence to medical care has yielded varying results. Pratt et al ${ }^{22}$ in a study of 72 participants with serious mental illnesses, reported adherence rates of $57 \%$ for psychiatric medications and $64 \%$ for medications for medical illnesses. Hansen et $\mathrm{al}^{23}$ in a study of 87,015 PWS with comorbid medical illnesses, found that adherence to medications for hypertension, hyperlipidemia, and diabetes was significantly greater among those who were adherent to antipsychotic medications, with an adjusted odds ratio of 6.9. In a study of 11,454 US veterans, Kreyenbuhl et $\mathrm{al}^{24}$ found poor adherence to medications for Type 2 diabetes mellitus (T2DM) in $43 \%$ of veterans with schizophrenia and T2DM, compared to poor adherence rates among 52\% of veterans with T2DM and no mental illness. Similarly, Nelson et $\mathrm{al}^{25}$ found that gaps in filled prescriptions for antihyperlipidemic medications were 44 days for veterans diagnosed with schizophrenia and T2DM, compared to 62 days for veterans with T2DM and no mental illness.

Piette et $\mathrm{al}^{26}$ noted that in a study of 1,686 veterans diagnosed with schizophrenia and comorbid diabetes and hypertension, differential rates of adherence depended on the type of medication prescribed to participants; findings suggest that treatment with antihypertensive and diabetes medications was associated with an increased risk for low adherence compared to antipsychotic medications. Dolder et $\mathrm{al}^{27}$ found that rates of adherence to antihypertensive agents in 89 veterans with psychotic disorders were similar to rates in 89 randomly selected, age-matched veterans without psychotic disorders; however, blood pressure control was significantly poorer over a 1 -year period in the participants 
with psychotic disorders. In contrast, Dolder et $\mathrm{a}^{28}$ found that among 76 middle-aged and older veterans with schizophrenia, 12-month adherence rates ranged from 52\%-64\% for antipsychotic medications and medications to treat hypertension, diabetes, and hyperlipidemia. Beebe et $\mathrm{al}^{29}$ in a study that compared the effectiveness of a telephone intervention to improve medication adherence $(n=15)$ to usual care $(n=14)$, found that average adherence rates to medications for medical illnesses was 33\% for the intervention group and $22 \%$ for the treatment-as-usual (TAU) group throughout the duration of the study.

\section{Consequences of nonadherence}

Partial or complete lack of adherence to medications is associated with several negative outcomes in PWS. ${ }^{8,30}$ Medication nonadherence is associated with an increased risk for relapse of psychosis, persistent symptoms, and suicide attempts. ${ }^{8,31}$ Among PWS experiencing a first episode of psychosis, symptom recurrence rates are an average of $77 \%$ within 1 year of stopping medications, and over $90 \%$ within 2 years of stopping medications. ${ }^{30}$ Bodén et $\mathrm{al}^{32}$ found that nonadherence to medications during the first week after discharge from an inpatient hospitalization was associated with a high risk for rehospitalization within 1 month of discharge. Length of hospital stay is also extended due to nonadherence. ${ }^{30}$ Finally, Gilmer et $\mathrm{al}^{5}$ found that average hospital costs in nonadherent inpatients were three times higher than costs for adherent inpatients, although pharmacy costs were higher among adherent compared to nonadherent inpatients.

\section{Current strategies to improve adherence}

Several support services are available to address specific problems with adherence. ${ }^{33}$ For example, therapeutic support services provide counseling, with the goal of identifying and modifying cognitive and motivational barriers to adherence. Cognitive-behavioral therapy (CBT) addresses inaccurate beliefs and negative perceptions about medications and the need for treatment. ${ }^{3} \mathrm{CBT}$ is often used in conjunction with motivational interviewing (MI), which seeks to resolve ambivalence about taking medications and addresses perceptions about the importance of taking medications and confidence in the ability to adhere to a medication regimen. ${ }^{34}$ Cognitive adaption training provides tailored environmental cues and supports to compensate for cognitive impairments that cause memory problems; these include alarms, pillboxes, activity checklists, and organization of personal belongings. ${ }^{33}$ Adherence/compliance therapy is a multifaceted approach that includes CBT, psychoeducation, and MI. ${ }^{3}$ Support services can also address logistic barriers to adherence, such as arranging transportation to pharmacies and obtaining insurance benefits. ${ }^{3}$

This review summarizes research from the past 10 years on interventions that examined the role of support services in promoting adherence to psychiatric medications and medications for medical illnesses among PWS. A literature search was conducted using the terms "medication adherence," "schizophrenia," and "support services" and "interventions" using Medline, PubMed, and CINAHL. Reference lists from published studies were also reviewed to identify additional research studies. A total of 22 articles were located using these search terms and are included in this review.

\section{Results}

Findings from this literature review are displayed in Tables $1-4$. Of the 22 studies reviewed, eleven significantly improved adherence to medications in the study samples, and five did not result in significant improvements.

\section{Support service interventions Family and/or clinician support/education}

Seven intervention studies examined the effectiveness of family and/or clinician support and education (Table 1). ${ }^{35-41}$ Two family studies showed promising findings. Farooq et $\mathrm{al}^{37}$ implemented an intervention to train family members to be key care supervisors of medication adherence (coupled with free medications). Findings indicated that medication adherence was significantly increased in the intervention group. ${ }^{37}$ Kopelowicz et al ${ }^{39}$ found that culturally adapted multifamily groups tailored to Spanish-speaking Mexican Americans, who had three individual and family psychotherapy sessions, a 1-day family workshop, and 24 family group sessions that focused on attitudes, beliefs, planned behaviors, and subjective norms, had increased adherence compared to multifamily groups only or TAU.

Interventions involving clinician support and education yielded varying results. Sajatovic et $\mathrm{a}^{41}$ examined the effectiveness of a psychosocial/psychoeducational customized adherence enhancement program for homeless people taking long-acting antipsychotic injections (LAIs), which focused on medication routines, communicating with clinicians, and managing adherence in the presence of substance abuse. The customized adherence enhancement program was associated with good adherence to LAIs in $76 \%$ of participants. Oral medication adherence improved to only $10 \%$ missed medication doses postintervention compared to $46 \%$ missed doses prestudy. However, only four out of 30 continued taking 


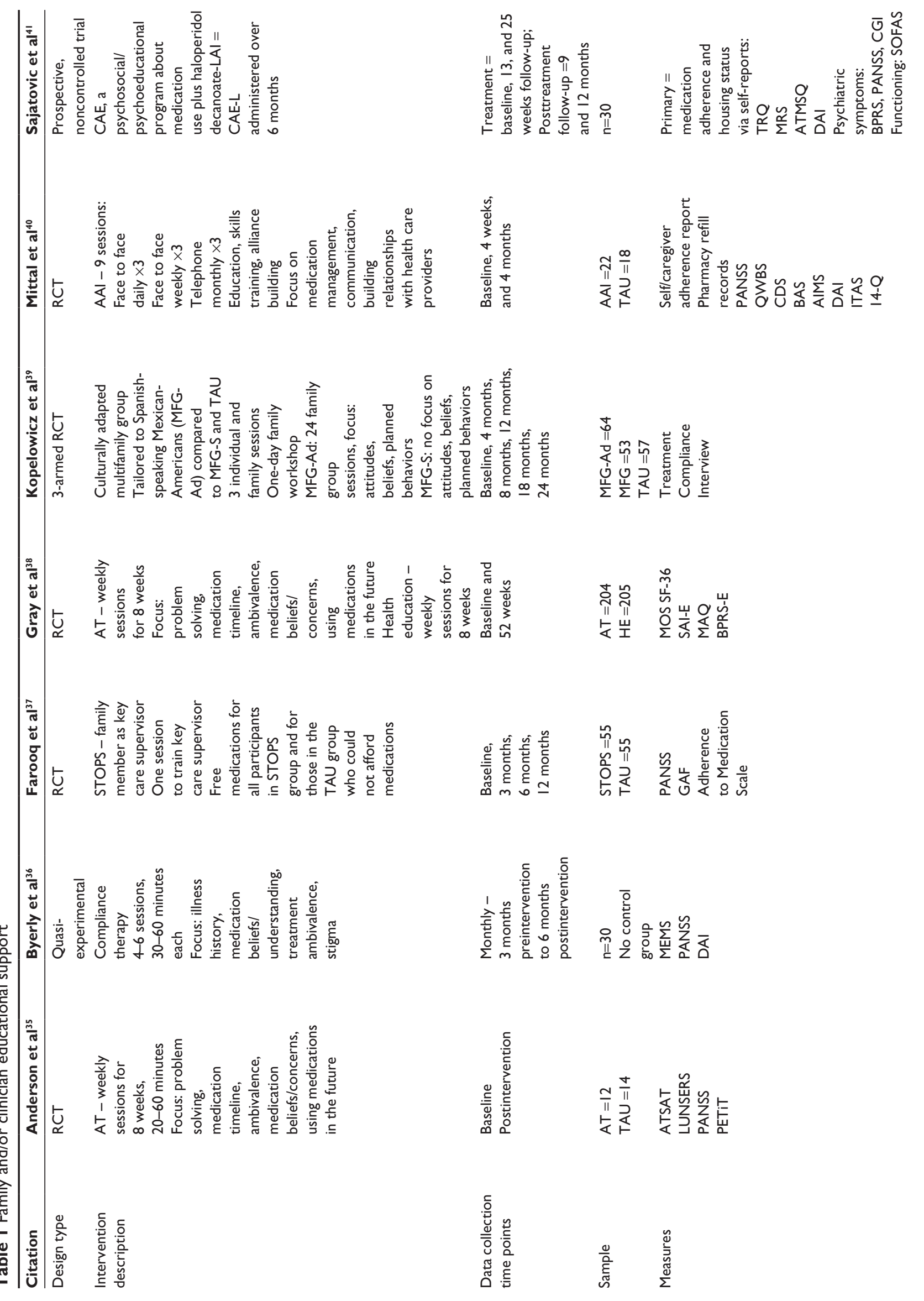




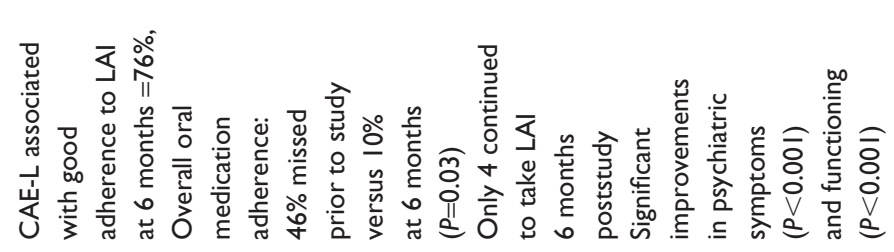

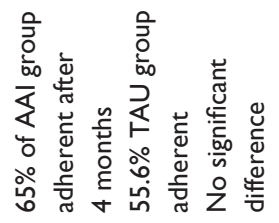

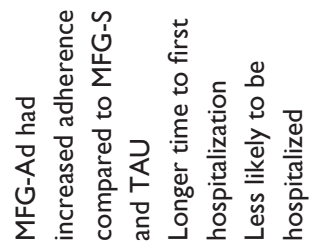

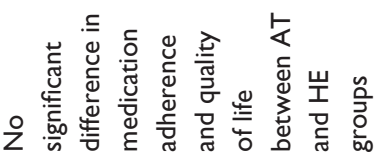

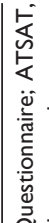

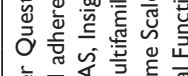

政它

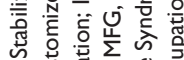

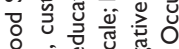

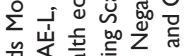

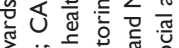

o

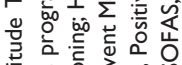

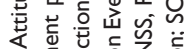

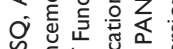

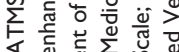

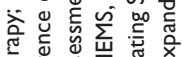

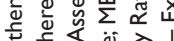

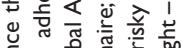

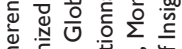

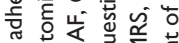

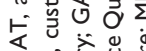

岸

传

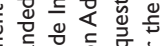

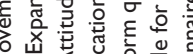

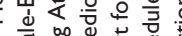

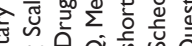

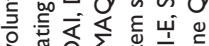

记

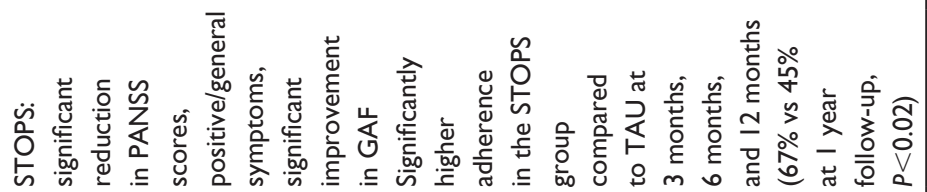

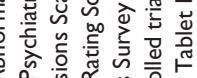

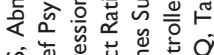

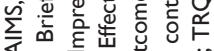

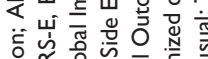

㝕佥 응

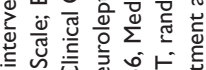

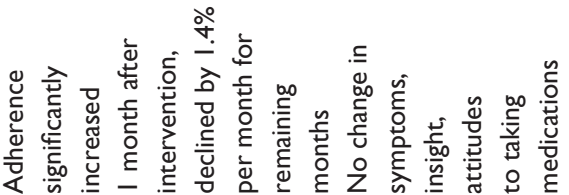

=

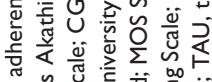

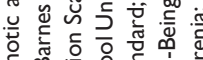

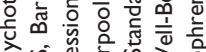

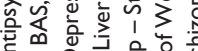

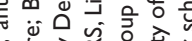

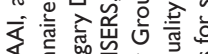

于े

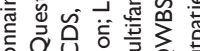

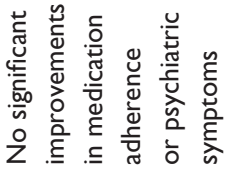

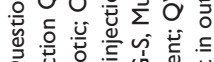

Oे

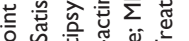

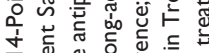

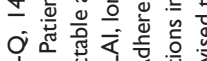

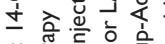

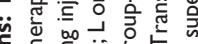

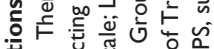

。

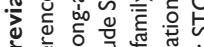

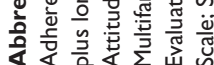

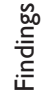


LAI 6 months poststudy. In contrast, Byerly et al $^{36}$ found that adherence did not increase after four to six sessions of compliance therapy that focused on illness history, and medication beliefs, understanding, ambivalence, and stigma of treatment. Anderson et $\mathrm{al}^{35}$ found no significant improvements in medication adherence following eight weekly sessions of adherence therapy that included problem solving, exploration of ambivalence toward medication beliefs, concerns, and using medications in the future. Similarly, Gray et $\mathrm{al}^{38}$ found that there was no significant difference in adherence between adherence therapy that included eight weekly sessions about problem solving, medication timeline, ambivalence, beliefs, and concerns about using them in the future versus eight weekly health education sessions. Mittal et $\mathrm{al}^{40}$ found that there was no significant difference between antipsychotic adherence therapy versus TAU following nine weekly sessions of daily, then weekly, face-to-face and telephone education, alliance building, and skills training in veterans aged 40 years and older.

\section{Technology-based services}

A variety of electronics-based strategies were studied, including text messages, phone reminders, pill counters, electronic pill dispensers, and a computerized program symptom alert system (Table 2). ${ }^{29,42-46}$ Pijnenborg et $\mathrm{al}^{44}$ used text messages in an intervention to examine the effectiveness of six weekly group sessions focusing on coping with cognitive impairment associated with schizophrenia. The study also involved instructions on how to send/receive text messages, including a total of 7 weeks of receiving text messages as a reminder to adhere to medications and other self-chosen treatment goals. Adherence to medications in the intervention group was $57 \%$ at baseline and $65 \%$ during the intervention, but fell to $48 \%$ at follow-up when text prompts were no longer being received. Granholm et $\mathrm{al}^{42}$ found that sending three sets of four text messages about medication adherence, socialization, and auditory hallucinations to people with schizophrenia significantly improved medication adherence for those living independently. Similarly, Montes et $\mathrm{a}^{43}$ found that after sending daily short-message-service reminders or texts for 3 months as a prompt to take medications, there was a significantly reduced score on the Medication Adherence Questionnaire (a four-item self-report of reasons for medication adherence failure, with a low score indicating better adherence) in the intervention group at 3 months, and at 6 months adherence was maintained.

Beebe et $\mathrm{al}^{29}$ found that study participants who received weekly telephone call reminders to take their medications

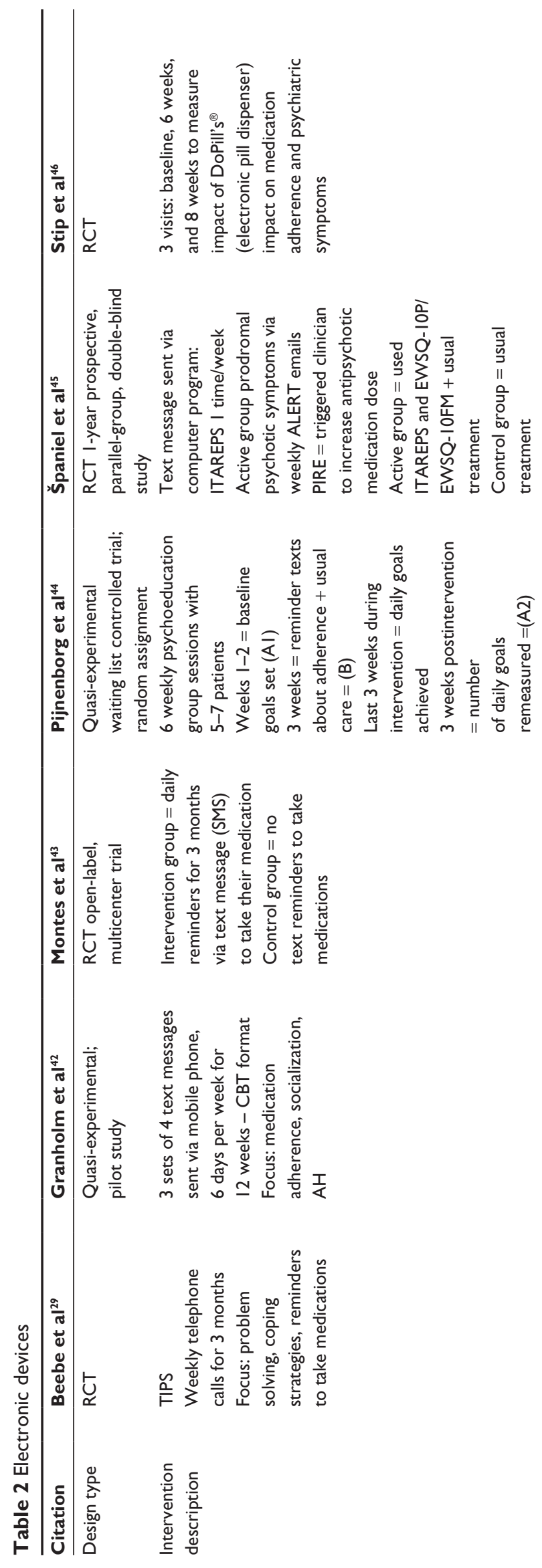



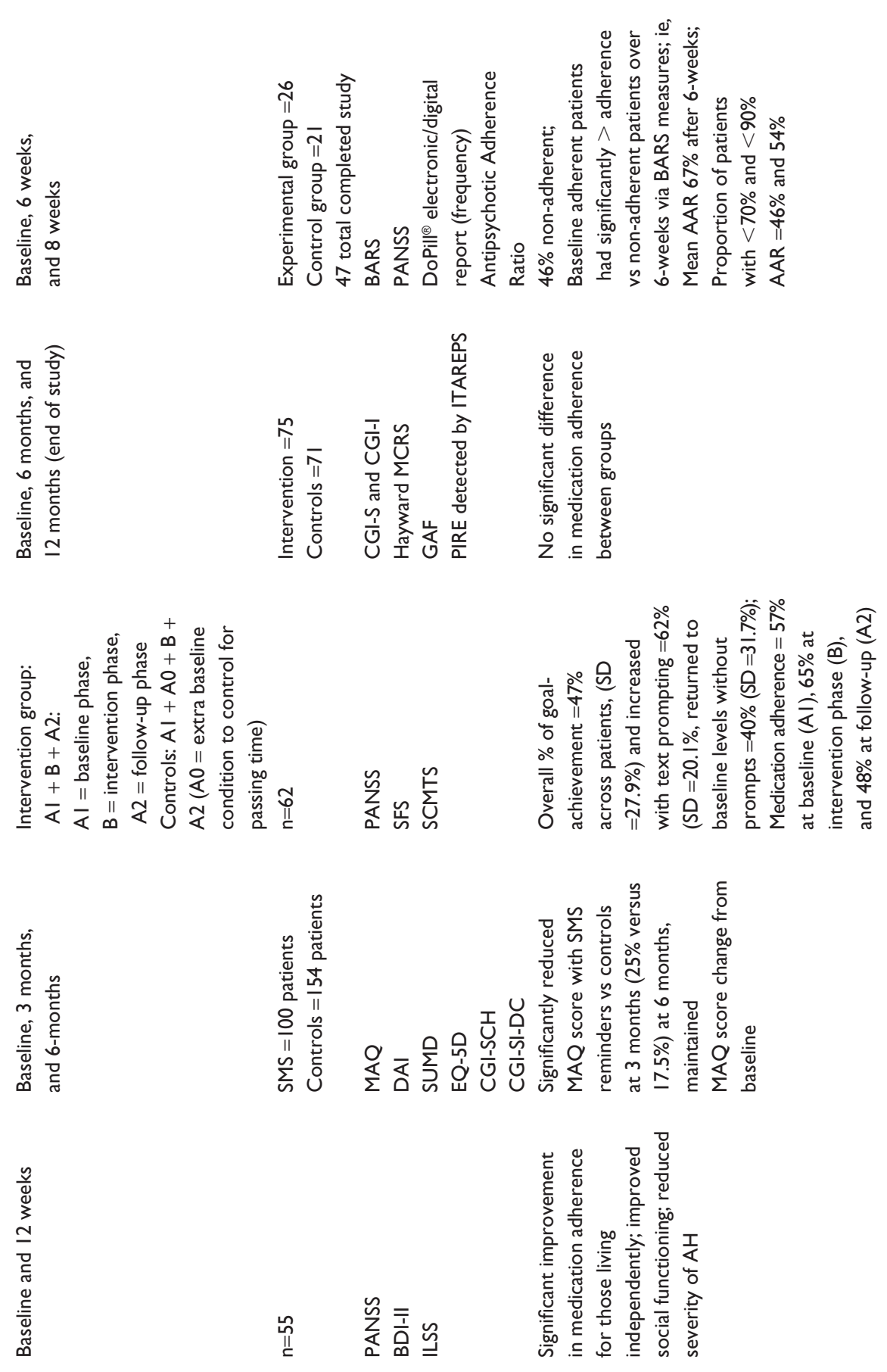

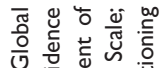

ฮู

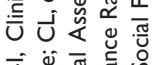

守荡

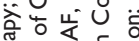

ब

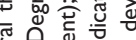

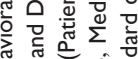

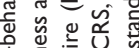

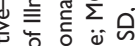

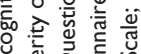

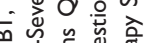

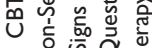

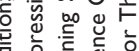

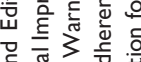

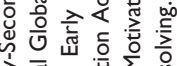

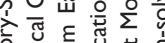

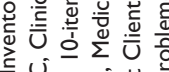

ธ

过市的的

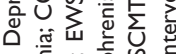

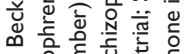

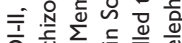

命出

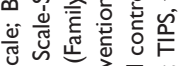

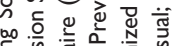

号.

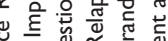

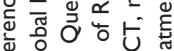

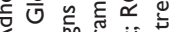

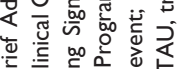

U U

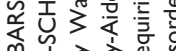

认ิ

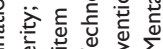

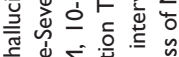

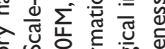

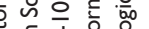

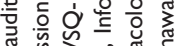

I

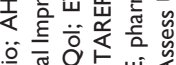

东

。声产高

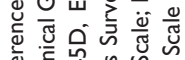

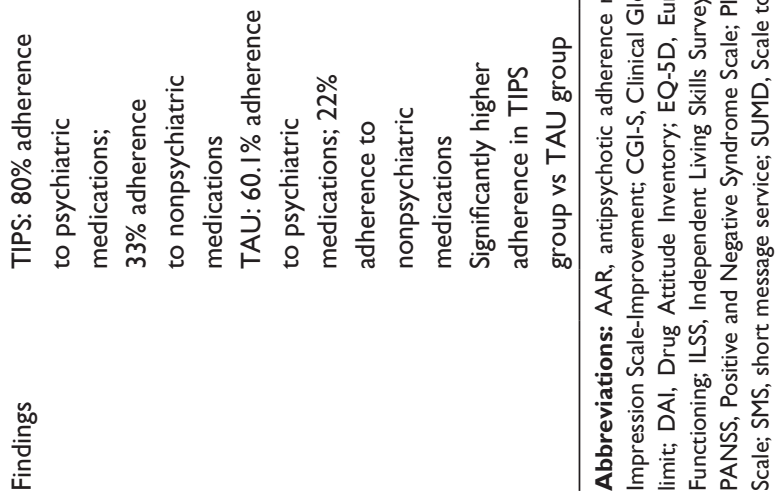




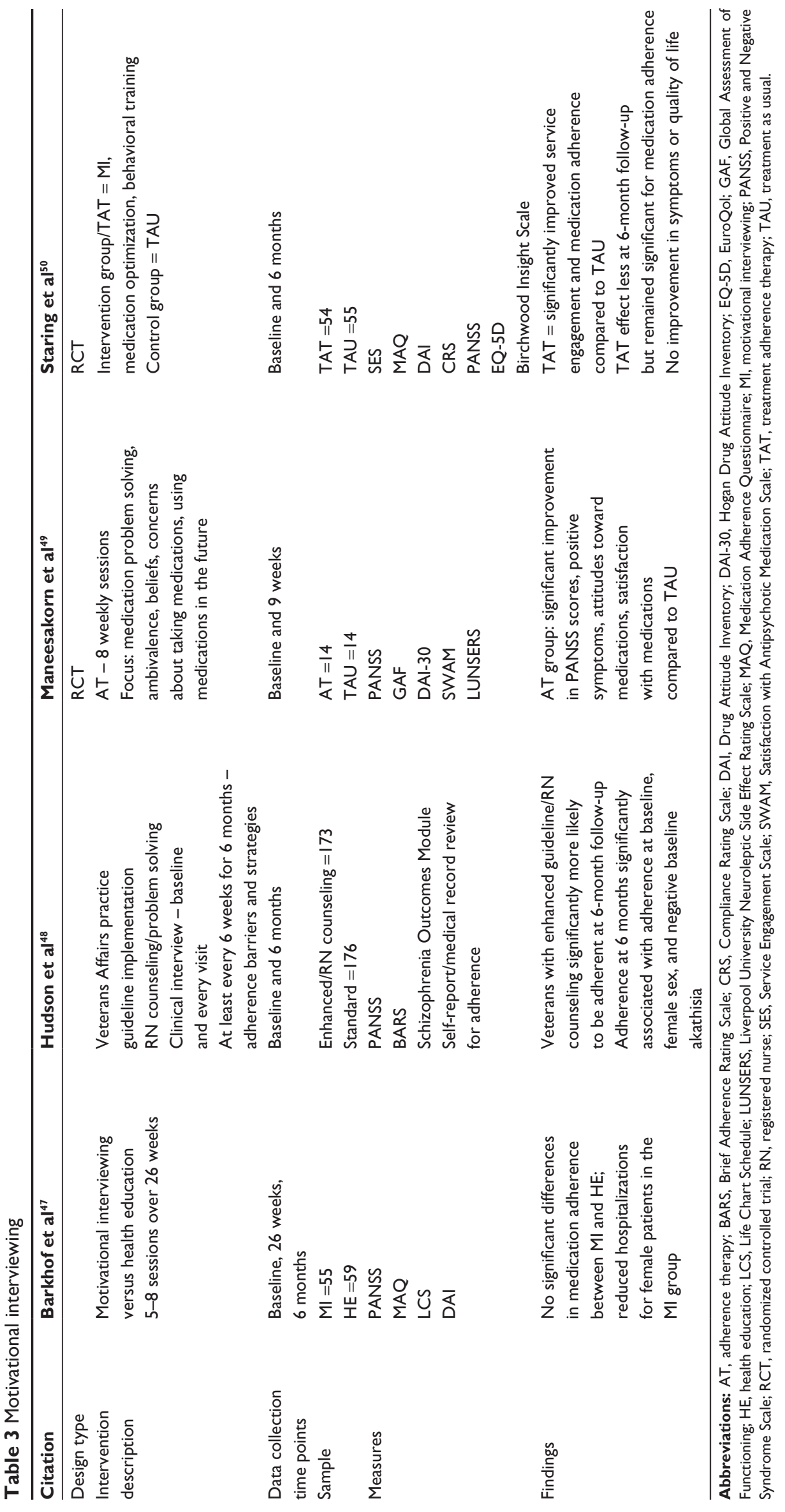




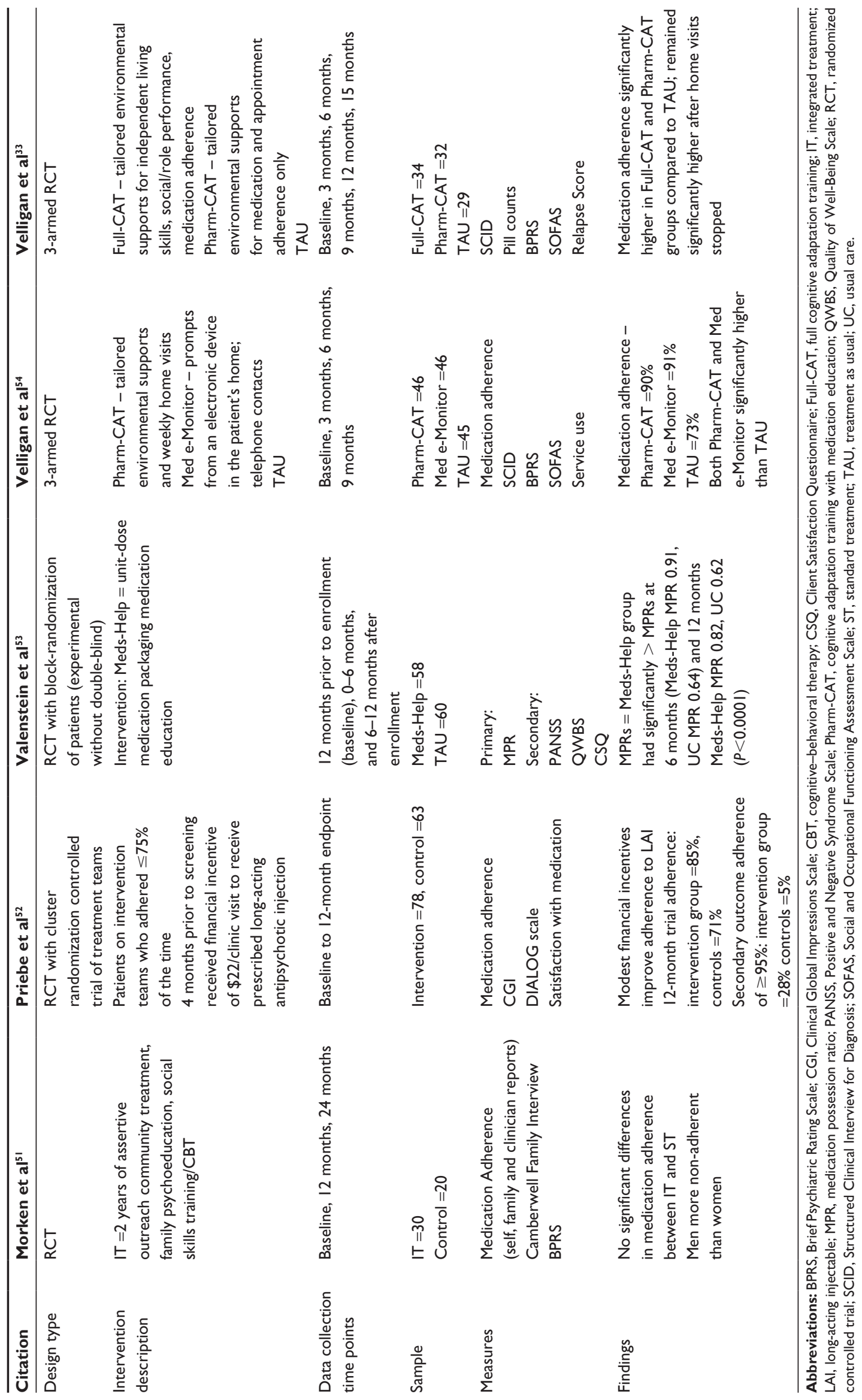


for psychiatric and medical conditions over 3 months had significantly higher adherence compared to TAU controls. Those in the intervention group were $80 \%$ adherent to psychiatric medications and $33 \%$ adherent to medications for medical conditions.

Stip et $\mathrm{al}^{46}$ found that after 8 weeks of using an electronic pill counter to assess medication adherence, $46 \%$ were nonadherent. The mean antipsychotic adherence ratio was $67 \%$ after 6 weeks. Participants who were adherent at baseline had significantly greater adherence versus those who were nonadherent at baseline. Španiel et $\mathrm{a}^{45}$ found that after 1 year of computer prompts to clinicians to increase antipsychotic medication doses when participants reported psychotic symptoms (via an electronic message), there was no significant difference in medication adherence in the intervention group compared to controls.

\section{Motivational interviewing interventions}

MI was used in conjunction treatment adherence therapy (TAT) and problem solving approaches (Table 3). ${ }^{47-50}$ Barkhof et $\mathrm{al}^{47}$ found that there were no significant differences in medication adherence after 26-week and 6-month interventions of MI versus health education. Staring et $\mathrm{al}^{50}$ examined the effectiveness of 6 months of TAT, which includes MI, medication optimization, and behavioral training, and found that TAT significantly improved medication adherence. Findings also indicated that, despite a decrease in effectiveness at the 6-month follow-up, adherence in the intervention group remained significantly higher than in the TAU group.

Hudson et $\mathrm{al}^{48}$ found that clinical interviews with a registered nurse who asked people to identify barriers to adherence and tailored strategies to overcome them via problem solving at each clinic visit (minimum of every 6 weeks) for 6 months significantly increased adherence at the 6-month follow-up. Adherence at 6 months was significantly associated with baseline adherence, female sex, and no akathisia at baseline. Maneesakorn et $\mathrm{al}^{49}$ examined the effectiveness of eight weekly sessions of adherence therapy which focused on medication problem-solving, beliefs/ attitudes/ambivalence toward taking medications, and taking medications in the future. Findings indicated that the participants in the adherence-therapy group showed significant improvements in positive symptoms, attitudes toward medications, and satisfaction with medications. In this study, medication adherence was not used as a primary outcome measure; the authors noted that the outcomes of symptom reduction and medication attitudes and satisfaction, rather than adherence, are indicators of the potential health gain due to the intervention. ${ }^{49}$

\section{Other support service interventions}

A variety of other support interventions were examined (Table 4) $;^{33,51-54}$ these included integrated treatment, ${ }^{51}$ financial incentives, ${ }^{52}$ a pharmacy-based intervention, ${ }^{53}$ and environmental supports. ${ }^{33,54}$ Morken et $\mathrm{al}^{51}$ found that a multifaceted program that implemented CBT along with assertive outreach community treatment, family psychoeducation, and social skills training, did not significantly improve medication adherence compared to TAU. Priebe et $\mathrm{al}^{52}$ found that modest financial incentives, in the amount of $\$ 22$ per clinic visit, to receive an LAI during a 12-month trial increased adherence from $<75 \%$ at baseline to $85 \%$, compared to $71 \%$ among controls. Greater than $95 \%$ adherence was seen in $28 \%$ of the intervention group, compared to $5 \%$ in the control group. Valenstein et al found that, compared to controls, patients using a pharmacy-based intervention that included unit-dose prescriptions of medications for psychiatric and medical conditions, medication education in packaging, and refill reminders mailed 2 weeks in advance for 6 and 12 months had significantly increased medication possession ratios (MPR, a measure that includes self-reports of adherence combined with pill counts and serum labs indicating presence of medication). ${ }^{53}$

Environmental supports involved the use of home visits and adaptation of participants' home environment to incorporate cues as reminders to adhere to treatment. Velligan et $\mathrm{al}^{54}$ found that home visits with full cognitive adaptation training, a tailored environmental support system aimed at improving independent living skills, and cognitive adaptation training with medication education, a tailored environmental support system for medication and appointment adherence, significantly improved medication adherence in both groups compared to the TAU group, and this difference remained significant after home visits stopped.

\section{Discussion}

Findings suggest that the utility of available support services to enhance medication adherence depend on a variety of factors, such as the PWS's attitudes toward treatment, perceptions of the need to take medications, and specific environmental and cognitive characteristics. Technological supports, such as mobile phone text message reminders, can be beneficial to PWS who are committed to medication adherence and are occasionally nonadherent due to forgetfulness. Similarly, interventions that focus on environmental cues to 
remind PWS to take their medications can be very helpful in patients with memory problems. ${ }^{54}$ In contrast, findings from this review suggest that therapeutic support services are more appropriate to PWS who are ambivalent toward taking medications and or deny the need to take medications. The most effective support service interventions are tailored to the specific needs of PWS, use a problem-solving approach to identify barriers to taking medications, and address ambivalence that PWS have toward committing to a life-long medication regimen.

Results of this literature review should be regarded with caution due to some limitations in the study designs. Adherence to psychiatric medications may depend on the participants' age, financial constraints/affordability of medications, ${ }^{9}$ adverse effects, severity of psychiatric symptoms, duration of illness, side effects, and therapeutic response. Younger age is a noteworthy predictor of nonadherence. ${ }^{4}$ However, in the studies reviewed here, only two focused on younger participants. One included family members as caregivers, ${ }^{39}$ in which the mean age of participants was $24.6 \pm 8.3$ years, and one included participants with recent onset of symptoms; ${ }^{31}$ the mean age of participants in this study was $25.1 \pm 4.5$ years. In the remaining studies, the mean ages of participants ranged from approximately 30-50 years, which limits generalizability to other age groups. Problems with medication adherence due to financial constraints and affordability of medications were not addressed in these studies, which is a noteworthy gap that warrants further research.

Medication side effects are known contributors to poor medication adherence among PWS. ${ }^{17}$ However, only three studies in this review included a measure of side effects as an outcome variable. Maneesakorn et $\mathrm{al}^{49}$ found reduced scores on the Liverpool University Neuroleptic Side Effect Rating Scale in the TAU group at a 9-week follow-up; the authors attribute this to the higher number of participants who were prescribed atypical antipsychotics in the TAU group. Hudson et $\mathrm{a}^{48}$ found greater adherence associated with negative baseline akathisia score. Finally, Sajatovic et $\mathrm{al}^{41}$ reported that in an adherence study that included LAIs, 40\% reported akathisia, but no significant changes were seen in body mass index or total cholesterol. Findings from this review suggest that further research is warranted to examine the degree to which adverse or side effects of the more frequently used atypical antipsychotics influence medication adherence, particularly related to the emergence of obesity and cardiovascular/metabolic problems.

Severity of psychotic symptoms and level of cognitive functioning can also influence medication adherence. In the studies included in this review, all but four assessed symptom severity at the outset of the studies. Rating measures included the Positive and Negative Syndrome Scale, the Clinical Global Impressions Scale, and the Brief Psychiatric Rating Scale. Across all studies that measured symptoms, baseline symptom severity scores ranged from very mildly to moderately ill. It is likely that PWS who experience very severe symptoms are excluded from medication adherence research because very severe symptoms prevent them from providing informed consent for participation. Consequently, research on medication adherence has limited generalizability toward PWS with severe psychotic symptoms, and unfortunately PWS who refuse or are unable to participate are most in need of support services to improve adherence. In addition, participants' treatment response was minimal in many of the studies, as evidenced by nonsignificant changes in symptom severity scores at the conclusion of the studies. ${ }^{33,35,36,42,43,45,53}$

Several authors also reported that PWS who refused to participate in the studies had considerable deficits in cognitive functioning. Limitations on eligibility based on cognitive functioning tended to limit the sample sizes, which ranged from 25-409; the majority of studies had less than 100 participants. Several authors pointed out that eligibility based on cognitive functioning and symptoms resulted in selection bias, which increased the likelihood that participants had higher levels of functioning. ${ }^{49}$

Very little longitudinal research has been conducted on medication adherence over the lifetime trajectory of illness among PWS; the maximum duration of time included in an adherence study was 4 years. ${ }^{53}$ Patterns of adherence may be unstable over time; Valenstein et $\mathrm{al}^{10}$ investigated patterns of medication adherence, measured by MPR over a 4 year period among 34,128 veterans with schizophrenia, and the findings suggested that over $60 \%$ of veterans had adherence problems at some point during the 4 year period. Findings also indicated that over a 4 year period, about $18 \%$ had consistently poor adherence, defined as MPRs $<0.8$ in all 4 years; $43 \%$ had inconsistent adherence, defined as MPRs $\geq 0.8$ in some years in the observation period, and $39 \%$ had consistently good adherence, defined as MPRs $\geq 0.8$ in all 4 years.

Very few reviewed studies focused on the effectiveness of support services in improving adherence to medications in the treatment of medical illnesses. Furthermore, it is important to note that in the study conducted by Beebe et $\mathrm{al}^{29}$ the telephone intervention problem-solving intervention improved adherence to psychiatric medications but not to medications for medical illnesses. Problems with adherence to medications for medical illnesses are by no means unique 
to PWS. Rates of medication nonadherence are about 50\% in the general population, ${ }^{55}$ which is essentially identical to rates of nonadherence to psychiatric medications among PWS. ${ }^{1}$ Low adherence to medications in the general population has been attributed to poor health literacy, intolerable side effects, and unaffordable copayments. ${ }^{55}$ In addition, people in the United States who are diagnosed with multiple chronic medical illnesses often receive fragmented care from several different providers, which results in complex medical regimens consisting of multiple medications. ${ }^{55}$

PWS who have complex comorbid medical illnesses likely experience barriers similar to those found in the general population, particularly related to fragmented care. ${ }^{26}$ A supportive therapeutic alliance has been shown to promote medication adherence in PWS, yet Piette et $\mathrm{al}^{26}$ have observed that fragmented and poorly coordinated medical care from multiple providers in different treatment settings is a considerable barrier to the development of a trusting relationship between patients and provider. In addition, PWS have an even greater risk for nonadherence compared to the general population due to problems with motivation and cognitive impairments that interfere with memory, attention, problemsolving, and health-related decision making. ${ }^{56}$

Adherence to medications that treat psychiatric and medical illnesses is essential for PWS to achieve recovery goals and optimize overall wellness, yet ongoing research strongly suggests that physical health status and overall wellness in this population are far from ideal. PWS suffer from higher-than-average rates of comorbid chronic medical illnesses and experience worse outcomes due to these illnesses compared to the general population, including higher rates of emergency hospital admissions, longer length of hospitalization for medical problems, and shorter length of survival. ${ }^{57-59}$ Much attention has been focused on the recent report that the life expectancy of PWS being served in the US state mental health system is 25 years shorter than that of the general population. ${ }^{60}$ These appalling morbidity and mortality statistics illustrate health disparities that are increasingly untenable to patients, clinicians, policy makers, and family members. ${ }^{61-63}$ A comprehensive initiative to reduce health disparities, integrate physical and mental health care, and improve mental and physical health status would need to address multiple barriers to effective health care among PWS, their providers, and health care delivery systems; the development of more-effective support services to improve adherence to medications for psychiatric and medical illnesses is foundational in this effort. ${ }^{64}$

\section{Implications for practice}

As this review illustrates, several strategies are available to prescribers to address medication adherence issues among PWS. The essential first step is the establishment of a trusting therapeutic relationship with the patient. ${ }^{7,16,20,21}$ In the event that inpatient hospitalization is needed, PWS should be included in treatment decisions as much as possible. ${ }^{20}$ Prior to implementation of support services, it is recommended that prescribers work with the patient to conduct a root-cause analysis of reasons for nonadherence; implementation would target specific support strategies to address them. It is recommended that prescribers address adherence to psychiatric medications as a priority and then address adherence to medications for medical illnesses as a secondary goal, since PWS have reported that stable psychiatric symptoms are an essential precursor to effective management of medical illnesses. ${ }^{56,65}$

Prescribers can also use cognitive strategies to link medication adherence to the patient's treatment goals, such as staying out of the hospital, living independently, maintaining normal glycemic control, or returning to work or school, as recommended in the Medication Treatment, Evaluation and Management evidence-based practice. ${ }^{66}$ Finally, prescribers can promote optimal medication adherence by regularly including PWS in decisions about medications and assessing patient knowledge and attitudes about medications throughout the provision of support services. ${ }^{66}$

\section{Disclosure}

This research was not funded by any extramural agency. The authors report no conflicts of interest in this work.

\section{References}

1. Zipursky RB. Why are the outcomes in patients with schizophrenia so poor? J Clin Psychiatry. 2014;75 Suppl 2:20-24.

2. Velligan DI, Lam YW, Glahn DC, et al. Defining and assessing adherence to oral antipsychotics: a review of the literature. Schizophr Bull. 2006;32(4):724-742.

3. Velligan DI, Weiden PJ, Sajatovic M, et al; Expert Consensus Panel on Adherence Problems in Serious and Persistent Mental Illness. The expert consensus guideline series: adherence problems in patients with serious and persistent mental illness. J Clin Psychiatry. 2009;70 Suppl 4:1-46; quiz 47.

4. Lang K, Meyers JL, Korn JR, et al. Medication adherence and hospitalization among patients with schizophrenia treated with antipsychotics. Psychiatr Serv. 2010;61(12):1239-1247.

5. Gilmer TP, Dolder CR, Lacro JP, et al. Adherence to treatment with antipsychotic medication and health care costs among Medicaid beneficiaries with schizophrenia. Am J Psychiatry. 2004;161(4):692-699.

6. Jónsdóttir H, Opjordsmoen S, Birkenaes AB, et al. Predictors of medication adherence in patients with schizophrenia and bipolar disorder. Acta Psychiatr Scand. 2013;127(1):23-33.

7. Misdrahi D, Petit M, Blanc O, Bayle F, Llorca PM. The influence of therapeutic alliance and insight on medication adherence in schizophrenia. Nord J Psychiatry. 2012;66(1):49-54. 
8. Novick D, Haro JM, Suarez D, Perez V, Dittmann RW, Haddad PM. Predictors and clinical consequences of non-adherence with antipsychotic medication in the outpatient treatment of schizophrenia. Psychiatry Res. 2010;176(2-3):109-113.

9. El-Mallakh P. Doing my best: poverty and self-care among individuals with schizophrenia and diabetes mellitus. Arch Psychiatr Nurs. 2007;21(1):49-60.

10. Valenstein M, Gaznoczy D, McCarthy JF, Myra Kim H, Lee TA, Blow FC. Antipsychotic adherence over time among patients receiving treatment for schizophrenia: a retrospective review. J Clin Psychiatry. 2006;67(10):1542-1550.

11. Glick ID, Stekoll AH, Hays S. The role of the family and improvement in treatment maintenance, adherence, and outcome for schizophrenia. J Clin Psychopharmacol. 2011;31(1):82-85.

12. Moritz S, Favrod J, Andreou C, et al. Beyond the usual suspects: positive attitudes towards positive symptoms is associated with medication noncompliance in psychosis. Schizophr Bull. 2013;39(4):917-922.

13. Baloush-Kleinman V, Levine SZ, Roe D, Shnitt D, Weizman A, Poyurovsky M. Adherence to antipsychotic drug treatment in earlyepisode schizophrenia: a six-month naturalistic follow-up study. Schizophr Res. 2011;130(1-3):176-181.

14. Beck EM, Cavelti M, Kvrgic S, Kleim B, Vauth R. Are we addressing the 'right stuff' to enhance adherence in schizophrenia? Understanding the role of insight and attitudes towards medication. Schizophr Res. 2011;132(1):42-49.

15. Kikkert MJ, Schene AH, Keoter MW, et al. Medication adherence in schizophrenia: Exploring patients', carers' and professionals' views. Schizophr Bull. 2006;32(4):786-794.

16. Dassa D, Boyer L, Benoit M, Bourcet S, Raymondet P, Bottai T. Factors associated with medication non-adherence in patients suffering from schizophrenia: a cross-sectional study in a universal coverage healthcare system. Aust N J Z Psychiatry. 2010;44(1):921-928.

17. Dibonaventura M, Gabriel S, Dupclay L, Gupta S, Kim E. A patient perspective of the impact of medication side effects on adherence: results of a cross-sectional nationwide survey of patients with schizophrenia. BMC Psychiatry. 2012;12:20.

18. Tranulis C, Goff D, Henderson DC, Freudenreich O. Becoming adherent to antipsychotics: a qualitative study of treatment-experienced schizophrenia patients. Psychiatr Serv. 2011;62(8):888-892.

19. Liu-Seifert H, Osuntokun OO, Feldman PD. Factors associated with adherence to treatment with olanzapine and other atypical antipsychotic medications in patients with schizophrenia. Compr Psychiatry. 2012;53(1):107-115

20. Day JC, Bentall RP, Roberts C, et al. Attitudes toward antipsychotic medication: the impact of clinical variables and relationships with health professionals. Arch Gen Psychiatry. 2005;62(7):717-724.

21. McCabe R, Bullenkamp J, Hansson L, et al. The therapeutic relationship and adherence to antipsychotic medication in schizophrenia. PLoS One 2012;7(4):e36080.

22. Pratt SI, Mueser KT, Driscoll M, Wolfe R, Bartels SJ. Medication nonadherence in older people with serious mental illness: prevalence and correlates. Psychiatr Rehabil J. 2006;29(4):299-310.

23. Hansen RA, Maciejewski M, Yu-Isenberg K, Farley JF. Adherence to antipsychotics and cardiometabolic medication: association with health care utilization and costs. Psychiatr Serv. 2012;63(9):920-928.

24. Kreyenbuhl J, Dixon LB, McCarthy JF, Soliman S, Ignacio RV, Valenstein M. Does adherence to medications for type 2 diabetes differ between individuals with vs without schizophrenia? Schizophr Bull. 2010;36(2):428-435.

25. Nelson LA, Graham MR, Lindsey CC, Rasu RS. Adherence to antihyperlipidemic medications and lipid control in diabetic Veterans Affairs patients with psychotic disorders. Psychosomatics. 2011;52(4): 310-318.

26. Piette JD, Heisler M, Ganoczy D, McCarthy JF, Valenstein M. Differential medication adherence among patients with schizophrenia and comorbid diabetes and hypertension. Psychiatr Serv. 2007;58(2): 207-212.
27. Dolder CR, Furtek K, Lacro JP, Jeste DV. Antihypertensive medication adherence and blood pressure control in patients with psychotic disorders compared to persons without psychiatric illness. Psychosomatics. 2005;46(2):135-141.

28. Dolder CR, Lacro JP, Jeste DV. Adherence to antipsychotic and nonpsychiatric medications in middle-aged and older patients with psychotic disorders. Psychosom Med. 2003;65(1):156-162.

29. Beebe LH, Smith K, Crye C, et al. Telenursing intervention increases psychiatric medication adherence in schizophrenia outpatients. $J \mathrm{Am}$ Psychiatr Nurses Assoc. 2008;14(3):217-224.

30. Zipursky RB, Menezes NM, Streiner DL. Risk of symptom recurrence with medication discontinuation in first-episode psychosis: a systematic review. Schizophr Res. 2014;152(2-3):408-414.

31. Morken G, Widen JH, Grawe RW. Non-adherence to antipsychotic medication, relapse and rehospitalisation in recent-onset schizophrenia. BMC Psychiatry. 2008;8:32.

32. Bodén R, Brandt L, Kieler H, Andersen M, Reutfors J. Early nonadherence to medication and other risk factors for rehospitalization in schizophrenia and schizoaffective disorder. Schizophr Bull. 2011; 133(1-3):36-41.

33. Velligan DI, Diamond PM, Mintz J, et al. The use of individually tailored environmental supports to improve medication adherence and outcomes in schizophrenia. Schizophr Bull. 2008;34(3):483-493.

34. Miller WR, Rollnick S. Motivational Interviewing: Helping People Change. 3rd ed. New York, NY: The Guilford Press; 2013.

35. Anderson KH, Ford S, Robson D, Cassis J, Rodrigues C, Gray R. An exploratory, randomized controlled trial of adherence therapy for people with schizophrenia. Int J Ment Health Nurs. 2010;19(5):340-349.

36. Byerly MJ, Fisher R, Carmody T, Rush AJ. A trial of compliance therapy in outpatients with schizophrenia or schizoaffective disorder. J Clin Psychiatry. 2005;66(8):997-1001.

37. Farooq S, Nazar Z, Irfan M, et al. Schizophrenia medication adherence in a resource-poor setting: randomised controlled trial of supervised treatment in out-patients for schizophrenia (STOPS). Br J Psychiatry. 2011;199(6):467-472.

38. Gray R, Leese M, Bindman J, et al. Adherence therapy for people with schizophrenia. European multicentre randomised controlled trial. $\mathrm{Br} \mathrm{J}$ Psychiatry. 2006;189:508-514.

39. Kopelowicz A, Zarate R, Wallace CJ, Liberman RP, Lopez SR, Mintz J. The ability of multifamily groups to improve treatment adherence in Mexican Americans with schizophrenia. Arch Gen Psychiatry. 2012; 69(3):265-273.

40. Mittal D, Owen RR, Lacro JP, et al. Antipsychotic adherence intervention for veterans over 40 with schizophrenia: results of a pilot study. Clin Schizophr Relat Psychoses. 2009;24(Suppl 1):S1171.

41. Sajatovic M, Levin J, Ramirez LF, et al. Prospective trial of customized adherence enhancement plus long-acting injectable antipsychotic medication in homeless or recently homeless individuals with schizophrenia or schizoaffective disorder. J Clin Psychiatry. 2013;74(12):1249-1255.

42. Granholm E, Ben-Zeev D, Link PC, Bradshaw KR, Holden JL. Mobile Assessment and Treatment for Schizophrenia (MATS): a pilot trial of an interactive text-messaging intervention for medication adherence, socialization, and auditory hallucinations. Schizophr Bull. 2012;38(3):414-425.

43. Montes JM, Medina E, Gomez-Beneyto M, Maurino J. A short message service (SMS)-based strategy for enhancing adherence to antipsychotic medication in schizophrenia. Psychiatry Res. 2012;200(2-3): 89-95.

44. Pijnenborg GH, Withaar FK, Brouwer WH, Timmerman ME, van den Bosch RJ, Evans JJ. The efficacy of SMS text messages to compensate for the effects of cognitive impairments in schizophrenia. $\mathrm{Br} J$ Clin Psychol. 2010;49(Pt 2):259-274.

45. Španiel F, Hrdlička J, Novák T, et al. Effectiveness of the information technology-aided program of relapse prevention in schizophrenia (ITAREPS): a randomized, controlled, double-blind study. J Psychiatr Pract. 2012;18(4):269-280. 
46. Stip E, Vincent PD, Sablier J, Guevremont C, Zhornitsky S, Tranulis C. A randomized controlled trial with a Canadian electronic pill dispenser used to measure and improve medication adherence in patients with schizophrenia. Front Pharmacol. 2013;4:100.

47. Barkhof E, Meijer CJ, de Sonneville LM, Linszen DH, de Haan L. The effect of motivational interviewing on medication adherence and hospitalization rates in nonadherent patients with multi-episode schizophrenia. Schizophr Bull. 2013;39(6):1242-1251.

48. Hudson TJ, Owen RR, Thrush CR, Armitage TL, Thapa P. Guideline implementation and patient-tailoring strategies to improve medication adherence for schizophrenia. J Clin Psychiatry. 2008;69(1):74-80.

49. Maneesakorn S, Robson D, Gournay K, Gray R. An RCT of adherence therapy for people with schizophrenia in Chiang Mai, Thailand. J Clin Nurs. 2007;16(7):1302-1312.

50. Staring AB, Van der Gaag M, Koopmans GT, et al. Treatment adherence therapy in people with psychotic disorders: randomised controlled trial. Br J Psychiatry. 2010;197(6):448-455.

51. Morken G, Grawe RW, Widen JH. Effects of integrated treatment on antipsychotic medication adherence in a randomized trial in recent-onset schizophrenia. J Clin Psychiatry. 2007;68(4):566-571.

52. Priebe $\mathrm{S}$, Yeeles $\mathrm{K}$, Bremner $\mathrm{S}$, et al. Effectiveness of financial incentives to improve adherence to maintenance treatment with antipsychotics: cluster randomised controlled trial. BMJ. 2013;347:f5847.

53. Valenstein M, Kavanagh J, Lee T, et al. Using a pharmacy-based intervention to improve antipsychotic adherence among patients with serious mental illness. Schizophr Bull. 2011;37(4):727-736.

54. Velligan D, Mintz J, Maples N, et al. A randomized trial comparing in person and electronic interventions for improving adherence to oral medications in schizophrenia. Schizophr Bull. 2013;39(5):999-1007.

55. Cutler DM, Everett W. Thinking outside the pillbox - medication adherence as a priority for health care reform. $N$ Engl J Med. 2010; 362(17):1553-1555.

56. Findlay LJ. Decision-Making Processes and Health Behaviors among Adults Diagnosed with Schizophrenia [dissertation]. Lexington: University of Kentucky; 2012.
57. DE Hert M, Correll CU, Bobes J, et al. Physical illness in patients with severe mental disorders. I. Prevalence, impact of medications and disparities in health care. World Psychiatry. 2011;10(1):52-77.

58. Marder SR, Essock SM, Miller AL, et al. Physical health monitoring of patients with schizophrenia. Am J Psychiatry. 2004;161(8): 1334-1349.

59. Schoepf D, Uppal H, Potluri R, Heun R. Physical comorbidity and its relevance on mortality in schizophrenia: a naturalistic 12-year follow-up in general hospital admissions. Eur Arch Psychiatry Clin Neurosci. 2014;264(1):3-28.

60. Manderscheid RW. Premature death among state mental health agency consumers: assessing progress in addressing a quiet tragedy. Int J Public Health. 2009;54 Suppl 1:7-8.

61. Cunningham C, Peters K, Mannix J. Physical health inequities in people with severe mental illness: identifying initiatives for practice change. Issues Ment Health Nurs. 2013;34(12):855-862.

62. Insel TR. Rethinking schizophrenia. Nature. 2010;468(7321): 187-193.

63. Parks J, Radke AQ, Mazade NA, editors. Measurement of Health Status for People with Serious Mental Illnesses. Alexandria, VA: National Association of State Mental Health Program Directors Medical Directors Council; 2010. Available from: http://www.nasmhpd.org/ docs/publications/MDCdocs/NASMHPDMedicalDirectorsHealthIndicatorsReport11-19-08.pdf. Accessed April 30, 2012.

64. De Hert M, Cohen D, Bobes J, et al. Physical illness in patients with severe mental disorders. II. Barriers to care, monitoring and treatment guidelines, plus recommendations at the system and individual levels. World Psychiatry. 2011;10(2):138-151.

65. El-Mallakh P. Evolving self-care in individuals with schizophrenia and diabetes mellitus. Arch Psychiatr Nurs. 2006;20(2):55-64.

66. Substance Abuse and Mental Health Services Administration. MedTEAM: Evaluating Your Program. HHS Publication No SMA-104548. Rockville, MD: Center for Mental Health Services, Substance Abuse and Mental Health Services Administration, US Department of Health and Human Services; 2010
Neuropsychiatric Disease and Treatment

\section{Publish your work in this journal}

Neuropsychiatric Disease and Treatment is an international, peerreviewed journal of clinical therapeutics and pharmacology focusing on concise rapid reporting of clinical or pre-clinical studies on a range of neuropsychiatric and neurological disorders. This journal is indexed on PubMed Central, the 'PsycINFO' database and CAS,

\section{Dovepress}

and is the official journal of The International Neuropsychiatric Association (INA). The manuscript management system is completely online and includes a very quick and fair peer-review system, which is all easy to use. Visit http://www.dovepress.com/testimonials.php to read real quotes from published authors. 